\title{
Inter-Conversion of Carbohydrate Reserves from Pollen Maturation to Rehydration in a Chili Pepper
}

\author{
Carolina Carrizo García ${ }^{1}$, Massimo Guarnieri ${ }^{2}$, Ettore Pacini ${ }^{2}$ \\ ${ }^{1}$ Instituto Multidisciplinario de Biología Vegetal (CONICET), Córdoba, Argentina; ${ }^{2}$ Dipartimento di Scienze Ambientali “G. Sar- \\ fatti”, Università degli Studi di Siena, Siena, Italia. \\ Email: ccarrizo@imbiv.unc.edu.ar
}

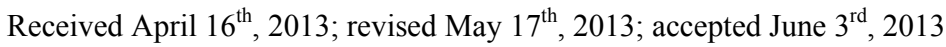

Copyright (C) 2013 Carolina Carrizo García et al. This is an open access article distributed under the Creative Commons Attribution License, which permits unrestricted use, distribution, and reproduction in any medium, provided the original work is properly cited.

\begin{abstract}
Carbohydrate metabolism is critical for male fertility. Carbohydrate reserves (soluble sugars and starch) were quantified in three advanced stages of pollen development, from the final maturation to rehydration, in a chili pepper cultivar (Capsicum annuum L. cv. Calypso Red) with partially dehydrated pollen, to define possible carbohydrate inter-conversions. At the same time, the activity of soluble enzymes involved in sucrolysis and amylolysis were quantified to reveal potential metabolic pathways. The carbohydrates found (sucrose, glucose, fructose, and starch) apparently inter-convert. There would be a close relation between enzymatic activities and substrates, and the carbohydrate reserves could be key factors on the regulation of enzymatic activities. All the enzymes tested were active, although the relevance of each one changed along pollen maturation and rehydration, defining different profiles of enzymatic activities for each stage. Some usually neglected enzymes (e.g. soluble neutral invertase) have shown an important role in the stages analyzed, suggesting alternative processes to evaluate in the studies of male fertility control.
\end{abstract}

Keywords: Pollen Advanced Development; Soluble Carbohydrates; Sucrolytic Enzymes; Amylolytic Enzymes

\section{Introduction}

Functional pollen is needed to successfully complete fertilization in plants. Pollen functioning relies on several characteristics, which can differ among species. The amount of water and the carbohydrate reserves are biochemical features considered relevant for pollen viability and longevity [1,2]; both features would also be related to each other (e.g. high water content and scarce sucrose would determine a short living pollen [2]). The pollen partially dehydrated, that is with less than $30 \%$ of water [3], is subjected to a series of drastic changes of water content and cellular activity in a brief period of time, from the moment they have reached the cytological maturity to the beginning of germination. Changes in the carbohydrate concentrations can occur in parallel to those variations, since carbohydrates are involved in different processes during pollen maturation, presentation and germination. Starch is considered an important reserve [1], which can be synthesized or hydrolyzed according to the needs (e.g. in response to environmental changes [4] or during pollen tube growth [5,6]), while sucrose may function as an osmotic regulator, as a membrane protector [7] and as a reserve [1,8]. Several enzymes metabo- lize pollen carbohydrates. The sucrolytic enzymes acid invertases and sucrose synthase have received most of the attention [e.g. 8-16], showing a critical role for male fertility. In contrast, amylolytic enzymes have been largely neglected (but see [15]).

An analysis of the content of carbohydrate reserves as well as a study of the activity of several soluble enzymes involved in their metabolization was carried out in different advanced pollen stages in a hot chili pepper ( Capsicum annuum L.) with partially dehydrated pollen. The aim of this work was to analyze the possible inter-conversion between the carbohydrates studied and reveal potential metabolic pathways, in an attempt to contribute to the understanding of how carbohydrate utilization would be involved in the male functioning throughout the final steps of maturation up to rehydration.

\section{Materials and Methods}

\subsection{Plant Material and Sampling}

Plants of the hot chili pepper (C. annuum) cv. Calypso Red were grown in a greenhouse at $32^{\circ} \mathrm{C} \pm 2{ }^{\circ} \mathrm{C}$ (optimal for flowering in this cultivar). Three developmental 
stages were studied: 1) immature bicellular pollen, collected one day before flower anthesis (1 DBA), 2) mature pollen collected the day of flower opening, and 3) rehydrated pollen, consisting of mature pollen rehydrated in vitro for $30 \mathrm{~min}$, when pollen tubes started to emerge. The culture medium of Mercado et al. [17] was used for the rehydration, without sucrose and with 15\% PEG 3350 as an osmoticant. A pre-hydration treatment was applied to facilitate rehydration, placing the pollen grains at $92 \%$ - 93\% of relative humidity for $1 \mathrm{~h}$. The assays were done at $26^{\circ} \mathrm{C} \pm 0.5^{\circ} \mathrm{C}$.

\subsection{Pollen Water Content}

Pollen water content was calculated indirectly based on the difference in volume between fresh (for 1 DBA and mature pollen)/rehydrated and desiccated pollen $(2 \mathrm{~h}$ at $100^{\circ} \mathrm{C}$ ); samples were submerged in immersion oil after being collected/treated. The formulas used to calculate the volume were: $4 / 3 \pi r^{3}$ for spherical grains, and $4 / 3 \pi$ (longest $r \times$ shortest $r^{2}$ ) for prolate spheroidal grains, where $r$ is the radium. The average volume was calculated from 100 pollen grains in each stage. The difference between the volume of fresh/rehydrated and desiccated pollen would represent the volume filled up by water, i.e. the percentage of water. The latter values were used to calculate the dry matter content at each pollen stage and the final weight for the rehydrated pollen.

\subsection{Carbohydrate Analysis}

For carbohydrate analysis, the samples were homogenized in distilled water (1 DBA and mature stages) or in the culture medium (rehydrated pollen) with a PRO200 homogenizer, were inactivated by heating in boiling water for $10 \mathrm{~min}$, and then centrifuged at $12,000 \mathrm{~g}$ and $4^{\circ} \mathrm{C}$ for $25 \mathrm{~min}$. The supernatants were used to quantify soluble carbohydrates while starch was quantified in the insoluble residues after three washes with distilled water. Samples were stored at $-80^{\circ} \mathrm{C}$. Each stage was analyzed by triplicate. Soluble carbohydrates were identified and quantified through HPLC analysis, using single sugars as standards, according to Carrizo García et al. [18]). Starch was quantified indirectly after digestion with the enzyme amyloglucosidase $\left(10 \mathrm{U} \cdot \mathrm{mL}^{-1}\right.$ in $50 \mathrm{mM}$ sodium acetate buffer, $\mathrm{pH}$ 4.8). After incubation for $2 \mathrm{~h}$ at $55^{\circ} \mathrm{C}$ under agitation, the glucose released was colorimetrically quantified using dinitrosalicylic acid reagent [15] in spectrophotomer ( $\lambda$ 560). Absolute and relative carbohydrate concentrations were calculated in relation to the dry matter content and fresh/rehydrated weight of the samples, respectively.

\subsection{Enzymatic Activities}

For the analysis of enzymatic activities, samples were prepared in an extraction buffer consisting of $1 \mathrm{mM}$ EDTA, $1 \mathrm{mM}$ DTT, $50 \mathrm{mM}$ sodium phosphate, $3 \mathrm{mM}$ $\mathrm{MgCl}_{2}$, and $2 \%$ glycerol $(\mathrm{pH}$ 7.4). The samples were homogenized and the supernatants were separated as described above. The activities assayed were soluble acid (Sai) and neutral (Sni) invertases, sucrose synthase in the cleavage direction (Susy), and amylases. Aliquots of every sample were incubated in a specific reaction medium for each enzyme. The reaction media were the following: $200 \mathrm{mM}$ sodium acetate $(\mathrm{pH} 4.0)$ and $10 \mathrm{mM}$ sucrose for the Sai; $50 \mathrm{mM}$ sodium phosphate $(\mathrm{pH}$ 7.3) and $10 \mathrm{mM}$ sucrose for the Sni; $50 \mathrm{mM}$ MES (pH 6.5), $10 \mathrm{mM}$ sucrose and $10 \mathrm{mM}$ UDP for the Susy; $25 \mathrm{mM}$ MOPS (pH 6) with solubilized starch $\left(1 \mathrm{mg} \cdot \mathrm{mL}^{-1}\right.$ for $1 \mathrm{~h}$ at $100^{\circ} \mathrm{C}$ ) for the amylases. The mixtures were incubated $1 \mathrm{~h}$ at $30^{\circ} \mathrm{C}$ in all the cases; the reactions were stopped by heating at $100^{\circ} \mathrm{C}$. Every enzymatic reaction was done three times for each stage. For the sucrolytic enzymes, sucrose hydrolysis was estimated through the changes of glucose and fructose. For the amylases, the quantity of starch hydrolyzed was calculated according to the changes of glucose and maltose. Glucose, fructose and maltose were identified and quantified as described above. Enzymatic activities were expressed as the amount of sugars released for min and total protein $\mathrm{mg}$; total proteins were quantified according to Bradford [19].

Mean values were calculated for the substances quantified and the enzymatic activities assayed at all three stages. Data from consecutive stages were compared pair wise using ANOVA $(\mathrm{P}=0.05)$.

\section{Results and Discussion}

\subsection{Pollen Water Content and Carbohydrate Fluctuations}

The pollen water content fluctuated along stages in the chili pepper studied. The water content was ca. $45 \%$ at 1 DBA, when the pollen was spherical, and then diminished to $25 \%$ in the mature pollen, which acquired a prolate spheroidal shape (Figure 1(a)). The water content increased during rehydration, reaching the $60 \%$; pollen grains have readopted the spherical shape, and pollen tubes may have started to emerge (Figure 1(a)). The variations of water content affected the carbohydrate concentrations, thus different degrees and directions of change could be observed for the absolute and relative values calculated (Figures 1(b) and (c)). The soluble carbohydrates found were sucrose, glucose and fructose. Sucrose was not the main soluble oligosaccharide in the mature pollen, in contrast to other chili pepper cultivars $[13,20]$, and it was completely hydrolyzed during rehydration (Figures 1(b) and (c)). Regarding the absolute values, the amount of sucrose diminished significantly 

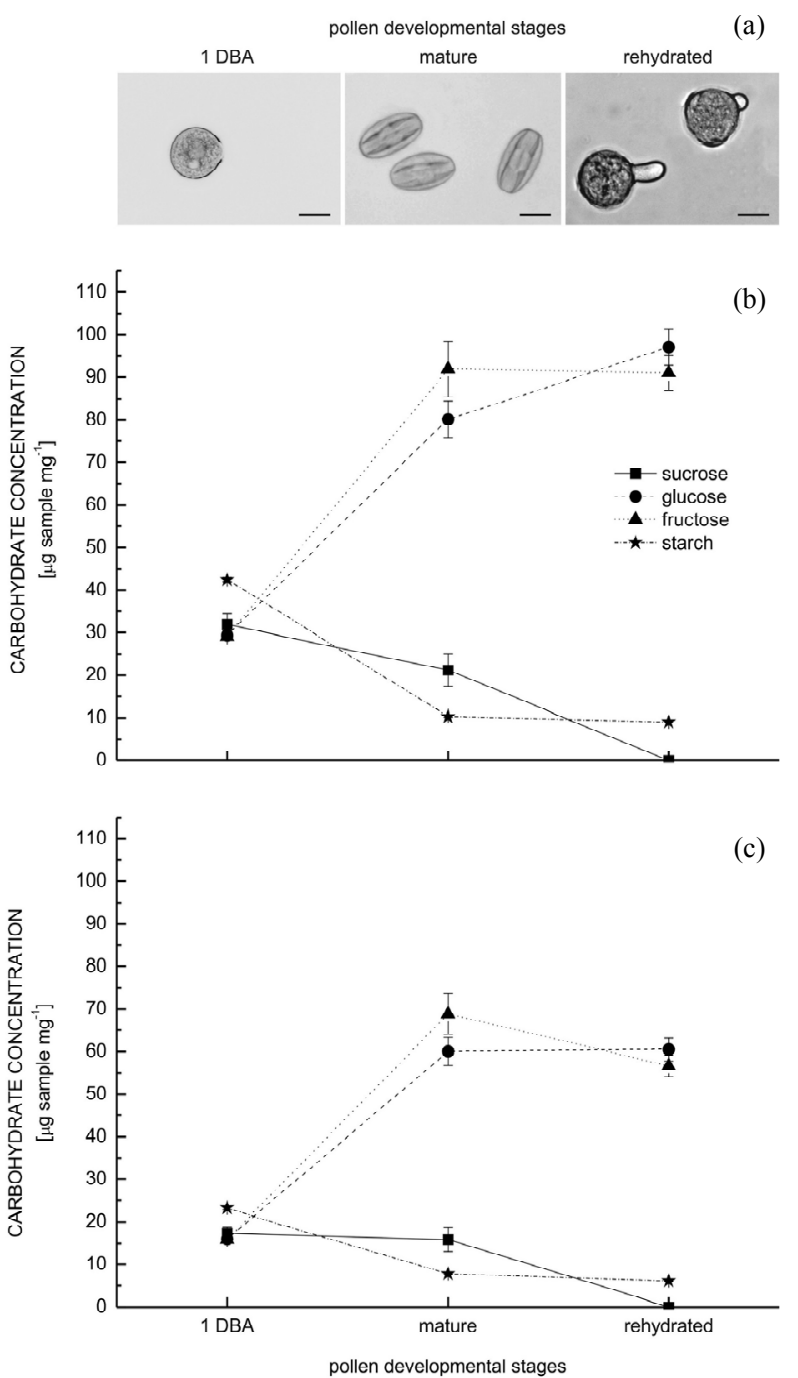

Figure 1. Pollen shape and carbohydrate concentrations in different pollen developmental stages in Capsicum annuum cv. Calypso Red. Mean values \pm SE. A: Pollen shape variations following changes in water content along stages (rehydrated pollen may have started to germinate). B: Absolute values calculated according to the dry weight of the samples. $C$ : Relative values calculated according to the fresh (1 DBA and mature stages) and rehydrated weights of the samples. $1 \mathrm{DBA}-1$ day before anthesis. Scale: $20 \mu \mathrm{m}$.

from 1 DBA to the mature pollen, while glucose and fructose increased significantly, ca. 2.7 and 3-fold respectively (Figure 1(b)). During rehydration, there was a significant increase of glucose, while fructose concentration did not change (Figure 1(b)). Starch was abundant 1 DBA, diminishing ca. 4 times in the mature and rehydrated pollen (the difference was not significant between these two stages; Figure 1(b)). The relative values of carbohydrate concentration followed a slightly different trend of change. Sucrose did not change significantly between $1 \mathrm{DBA}$ and the mature pollen, while glucose and fructose increased significantly, ca. 3.7 and 4-fold respectively (Figure 1(c)). The concentration of glucose did not change during rehydration, while the amount of fructose decreased significantly (Figure 1(c)). The relative amount of starch was reduced ca. 3 times from 1 DBA to the mature pollen, and then slightly during rehydration (Figure 1(c)); both reductions were statistically significant. Even though a 1:1 stoichiometric relationship between glucose and fructose was not kept within every stage, glucose and fructose quantities were not significantly different, either for the absolute or the relative values. A dilution effect can be observed for all relative values, in different extent for each stage due to the dissimilar water contents. Because of that, the osmotic pressure caused by sucrose, and even glucose and fructose, would vary following the natural changes in water content along stages, then modifying the hydric relationship between pollen and the surrounding environment.

The carbohydrate variations along the stages analyzed would evidence possible inter-conversions between the different substances quantified, considering that the pollen would be independent from the rest of the plant by 1 DBA [21], and no nutrients were added to the culture medium during rehydration. The increment of glucose and fructose towards maturation can be related to sucrose cleavage, and particularly to starch hydrolysis (glucose equilibrates with fructose via the hexose phosphate pool). During rehydration, although sucrose was completely hydrolyzed and a minor amount of starch was further digested, the trend of change for glucose and fructose would show that at least a small amount of both substances has been used in other metabolic pathways, possibly cell wall synthesis and/or glycolysis (energy), given that pollen tubes have started to emerge. In general, there is a tendency to provide hexoses that can be metabolized later during germination and pollen tube growth. Soluble carbohydrates consumption during those processes has been previously recorded [e.g. 5,8,22]. Regarding the relation between sucrose and hexoses, Pressman et al. [14] suggested the existence of a 'futile cycle' of sucrose cleavage and synthesis during pollen development, according to their own data and previous records. That cycle includes sucrose re-synthesis and storage in advanced stages [14], which would be cleaved again upon pollen rehydration and germination. The pollen of the chili pepper analyzed this time may be more efficient on that matter since hexoses seem to be accumulated instead of sucrose.

\subsection{Sucrolytic Activities}

In parallel to the carbohydrate temporal fluctuations, all the enzymatic activities quantified also changed. The sucrolytic activities increased from 1 DBA to the mature pollen, matching the reduction of the absolute sucrose 
concentration, and later decreased along with sucrose depletion during rehydration (Figure 2(a)). However, only the Sni increment between 1 DBA and the mature pollen and the Sai reduction between the mature and rehydrated pollen were statistically significant. None change was significant for the Susy activity. Changes of sucrolytic activities have been registered in several species along pollen development [11-15,20,23] or during pollen tube growth $[8,18]$, but it is not a rule [e.g. 10]. In the case reported here, invertases carried out most of sucrose hydrolysis, and presented the most important changes in their levels of activity. The proportion of the total sucrolytic activity accomplished for each enzyme was different within every stage (Figure 2(a)), that is: 1) the Sai activity was the highest while the Sni and Susy activities were lower and similar in the stage 1 DBA (significant differences between Sai/Sni and Sai/Susy); 2) the Sai was still the highest in the mature pollen but the Sni has increased significantly, while the Susy activity was by far the lowest (significant differences between Sai/Susy and Sni/Susy); 3) during rehydration, the Sni activity was the highest, followed by the Sai, while the Susy remained as the lowest one (significant differences only between Sni/Susy). It is worth mentioning that the Sni activity was high in relation to the Sai activity, which is the form of invertase usually studied. Therefore, the Sni may have an important role during these advanced pollen stages. Since both soluble invertases are located in different cellular compartments (Sai in vacuoles and Sni in the cytoplasm [24]), maybe their levels of activity are related to their specific locations (and possibly with different functions) and/or to an uneven distribution of sucrose. About that, Aloni et al. [20] mentioned a possible compartamentation of sucrose, separated from the Sai, in another chili pepper pollen, meaning that sucrose would be unevenly distributed inside the pollen.

\subsection{Amylolytic Activities}

Amylolytic activities decreased significantly to one third from 1 DBA to the mature pollen, and then slightly, not significantly, during rehydration (Figure 2(b)), i.e. amylases activities decreased while starch was consumed. As indicated by the products of amylolysis, $\alpha$ - and $\beta$-amylase activities (glucose and maltose respectively) would vary between stages (Figure 2(b)). At 1 DBA, the quantity of maltose released was 100 times higher than the quantity of glucose released (Figure 2(b)). The glucose released was tripled while the production of maltose was reduced 3 times in the mature pollen, but the latter was still ca. 10 times higher than the quantity of glucose (Figure 2(b)). During pollen rehydration the glucose released increased 4 times while maltose production was reduced one third, then hardly duplicating the amount of glucose (Figure 2(b)). Therefore, the $\beta$-amylase activity
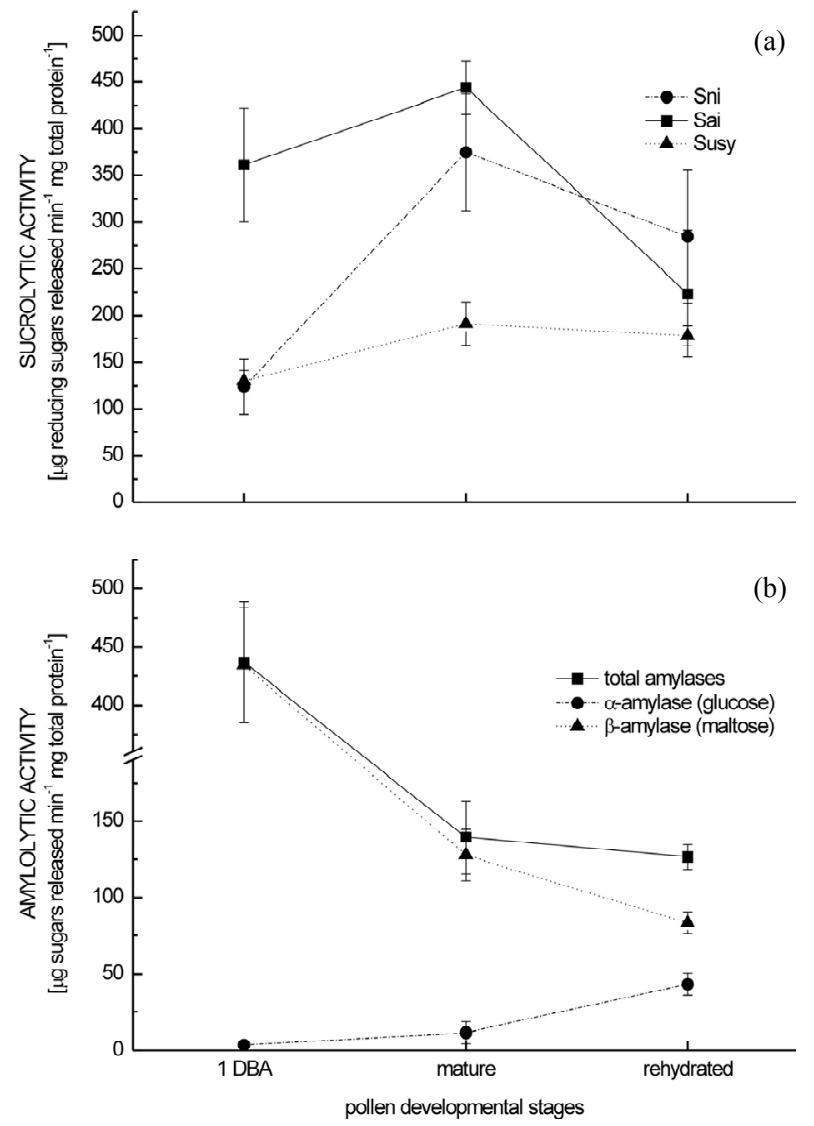

Figure 2. Activity of soluble enzymes involved in carbohydrate metabolism at different pollen developmental stages in Capsicum annuum cv. Calypso Red. Mean values \pm SE. A: Soluble sucrolytic activities. B: Amylolytic activities $(\alpha$ - and $\beta$-amylase activities are distinguished by their products of hydrolysis, glucose and maltose, respectively). 1 DBA: 1 day before anthesis, Sni: soluble neutral invertase, Sai: soluble acid invertase, Susy: sucrose synthase.

would decrease significantly between stages whereas the $\alpha$-amylase activity would increase significantly (Figure 2(b)). This trend for the $\alpha$-amylase has also been observed in Amaryllis during pollen germination [6]. Castro and Clément [15] have also recorded different levels of $\alpha$ - and $\beta$-amylase activities in the pollen of Lilium, which showed different patterns of fluctuation along pollen development as well. Here, the $\beta$-amylase would be the more active form regardless the gradual activity diminution. Maltose would be the main product of starch hydrolysis in this chili pepper pollen, but a maltose increment was not observed as starch was naturally digested. It can be hypothesized that maltose has to be further hydrolyzed to glucose in vivo, probably triggering the observed increment of $\alpha$-amylase activity.

\section{Conclusion}

It seems to be a logical inter-conversion between the 
carbohydrates analyzed. Besides, there would be a close relation between enzymatic activities and substrates, and the carbohydrate reserves (and perhaps exogenous nutrients when present) could be key factors on the regulation of enzymatic activities. All the enzymes tested were actively involved, in different and variable degrees, in pollen maturation and rehydration. Each stage was characterized by a different profile of enzymatic activities, in which the relevance of each enzyme was different. This trait could indicate different main pathways (and sites) of the carbohydrate reserve metabolization in each stage. The current results present alternative processes to evaluate, such as sucrolysis by the Sni and amylolysis by the $\beta$-amylase, in the studies of male fertility control.

\section{Acknowledgements}

CCG thanks the financial support of CONICET and FONCyT (Argentina). Italian authors are indebted to Piano di Ricerca dell'Ateneo (Siena University, Italia) for founding pollen research.

\section{REFERENCES}

[1] E. Pacini, "Types and Meaning of Pollen Carbohydrate Reserves," Sexual Plant Reproduction, Vol. 9, No. 6, 1996, pp. 362-366. doi:10.1007/BF02441957

[2] E. Pacini, M. Guarnieri and M. Nepi, "Pollen Carbohydrates and Water Content during Development, Presentation, and Dispersal: A Short Review," Protoplasma, Vol. 228, No. 1-3, 2006, pp. 73-77. doi: s00709-006-0169-z

[3] M. Nepi, G. G. Franchi and E. Pacini, "Pollen Hydration Status at Dispersal: Cytophysiological Features and Strategies," Protoplasma, Vol. 216, No. 3-4, 2001, pp. 171180. doi:10.1007/BF02673869

[4] J. L. Vesprini, M. Nepi, L. Cresti, M. Guarnieri and E. Pacini, "Changes in Cytoplasmic Carbohydrate Content during Helleborus Pollen Presentation," Grana, Vol. 41, No. 1, 2002, pp. 16-20. doi:10.1080/00173130260045459

[5] D. B. Dickinson, "Rapid Starch Synthesis Associated with Increased Respiration in Germinating Lily Pollen," Plant Physiology, Vol. 43, No. 1, 1968, pp. 1-8. doi:10.1104/pp.43.1.1

[6] M. B. Singh, C. P. Malik and N. Thapar, "Changes in the Activities of Some Enzymes of Carbohydrate Metabolism in Amaryllis vittata Pollen Suspension Cultures," Plant and Cell Physiology, Vol. 19, No. 4, 1978, pp. 677-684.

[7] F. A. Hoekstra, M. Crowe and J. H. Crowe, "Differential Desiccation Sensitivity of Corn and Pennisetum Pollen Linked to Their Sucrose Contents," Plant, Cell and Environment, Vol. 12, No. 1, 1989, pp. 83-91. doi:10.1111/j.1365-3040.1989.tb01919.x

[8] N. Nakamura, M. Sado and Y. Arai, "Sucrose Metabolism during the Pollen Growth of Camellia japonica Pollen," Phytochemistry, Vol. 19, No. 2, 1980, pp. 205-209. doi:10.1016/S0031-9422(00)81961-5

[9] J. Tupý, "Sugar Absorption, Callose Formation and the
Growth Rate of Pollen Tubes," Biologia Plantarum, Vol. 2, No. 3, 1960, pp. 169-180. doi:10.1007/BF02920646

[10] M. B. Singh and R. B. Knox, "Invertases of Lilium Pollen. Characterization and Activity during in Vitro Germination," Plant Physiology, Vol. 74, No. 3, 1984, pp. 510515. doi:10.1104/pp.74.3.510

[11] M. Goetz, D. E. Godt, A. Guivarc'h, U. Kahmann, D. Chriqui and T. Roitsch, "Induction of Male Sterility in Plants by Metabolic Engineering of the Carbohydrate Supply," Proceedings of the National Academy of Sciences of the United State of America, Vol. 98, No. 11, 2001, pp. 6522-6527. doi:10.1073/pnas.091097998

[12] P. K. Koonjul, J. S. Minhas, C. Nunes, L. S. Sheroan and H. S. Saini, "Selective Transcriptional Down-Regulation of Anther Invertases Precedes the Failure of Pollen Development in Water-Stressed Wheat," Journal of Experimental Botany, Vol. 56, No. 409, 2005, pp. 179-190. doi:10.1093/jxb/eri018

[13] E. Pressman, R. Shaked and N. Firon, "Exposing Pepper Plants to High Day Temperatures Prevents de Adverse Low Night Temperature Symptoms," Physiologia Plantarum, Vol. 126, No. 4, 2006, pp. 618-626. doi:10.1111/j.1399-3054.2006.00623.x

[14] E. Pressman, R. Shaked, S. Shen, L. Altahan and N. Firon, "Variations in carbohydrate content and sucrose-metabolizing enzymes in tomato (Solanum lycopersicum L.) stamen parts during pollen maturation," American Journal of Plant Sciences, Vol. 3, No. 2, 2012, pp. 252-260. doi:10.4236/ajps.2012.32030

[15] J. A. Castro and C. Clément, "Sucrose and Starch Catabolism in the Anther of Lilium during Its Development: A Comparative Study among the Anther Wall, Locular Fluid and Microspore/Pollen Fraction," Planta, Vol. 225, No. 6, 2007, pp. 1573-1582. doi:10.1007/s00425-006-0443-5

[16] D. Persia, G. Cai, C. Del Casino, C. Faleri, M. T. M. Willemse and M. Cresti, "Sucrose Synthase Is Associated with the Cell Wall of Tobacco Pollen Tubes," Plant Physiology, Vol. 147, No. 4, 2008, pp. 1603-1618. doi:10.1104/pp.108.115956

[17] J. A. Mercado, R. Fernández-Muñoz and M. A. Quesada, "In Vitro Germination of Pepper Pollen in Liquid Medium," Scientia Horticulturae, Vol. 57, No. 4, 1994, pp. 273-281.doi:10.1016/0304-4238(94)90110-4

[18] C. Carrizo García, M. Guarnieri and E. Pacini, "Soluble Carbohydrates Content in Tomato Pollen and Its Variations along and between Blooming Periods," Scientia Horticulturae, Vol. 125, No. 3, 2012, pp. 524-527. doi:10.1016/j.scienta.2010.04.026

[19] M. M. Bradford, "A Rapid and Sensitive Method for the Quantitation of Microgram Quantities of Protein Using the Principle of Dye Binding," Analytical Biochemistry, Vol. 72, No. 1-2, 1976, pp. 143-147. doi:10.1016/0003-2697(76)90527-3

[20] B. Aloni, M. Peet, M. Pharr and L. Karni, "The Effect of High Temperature and High Atmospheric $\mathrm{CO}_{2}$ on Carbohydrate Changes in Bell Pepper (Capsicum annuum) Pollen in Relation to Its Germination," Physiologia Plantarum, Vol. 112, No. 4, 2001, pp. 505-512. 
doi:10.1034/j.1399-3054.2001.1120407.x

[21] F. A. Hoekstra and T. van Roekel, "Desiccation Tolerance of Papaver dubium L. Pollen during Its Development in the Anther," Plant Physiology, Vol. 88, No. 3, 1988, pp. 626-632. doi:10.1104/pp.88.3.626

[22] C. Carrizo García, M. Guarnieri and E. Pacini, "Tomato Pollen Tube Development and Carbohydrate Fluctuations in the Autotrophic Phase of Growth," Acta Physiologiae Plantarum, Vol. 34, No. 6, 2012, pp. 2341-2347. doi:10.1007/s11738-012-1037-4

[23] S. N. Oliver, J. T. van Dongen, S. C. Alfred, E. A. Ma- mun, X. Zhao, H. S. Saini, S. F. Fernandes, C. L. Blanchard, B. G. Sutton, P. Geigenberger, E. S. Dennis and R. Dolferus, "Cold-Induced Repression of the Rice AntherSpecific Cell Wall Invertase Gene OSINV4 Is Correlated with Sucrose Accumulation and Pollen Sterility," Plant, Cell and Environment, Vol. 28, No. 12, 2005, pp. 15341551. doi:10.1111/j.1365-3040.2005.01390.x

[24] T. Roitsch and M. C. González, "Function and Regulation of Plant Invertases: Sweet Sensations," Trends in Plant Science, Vol. 9, No. 12, 2004, pp. 606-613. doi:10.1016/i.tplants.2004.10.009

\author{
Abbreviations \\ DBA-Day before Anthesis; \\ Sai-Soluble Acid Invertase; \\ Sni-Soluble Neutral Invertase; \\ Susy-Sucrose Synthase.
}

